\title{
Prática da utilização de lancetas ou agulhas na automonitorização da glicemia capilar no domicílio
}

\author{
Use of lancets or needles in the blood glucose self-monitoring at home
}

Práctica de uso de lancetas o agujas en la automonitorización de la glucosa sanguínea en domicilio

\section{Carla Regina de Souza Teixeira', Maria Lucia Zanetti', Camila Aparecida Pinheiro Landim", Flávia Fernanda Luchetti Rodrigues", Ellen Cristina Barbosa Santos", Tânia Alves Canata Becker", Ione Carvalho Pinto', Francisco José Albuquerque Paula'I}

' Universidade de São Paulo, Escola de Enfermagem de Ribeirão Preto. Ribeirão Preto-SP, Brasil.

"Universidade de São Paulo, Escola de Enfermagem de Ribeirão Preto, Programa Pós-Graduação em Enfermagem Fundamental (Doutoranda). Ribeirão Preto-SP, Brasil.

II Universidade de São Paulo, Faculdade de Medicina de Ribeirão Preto. Ribeirão Preto-SP, Brasil.

\author{
Submissão: 27-06-2011 Aprovação: 04-10-2012
}

\section{RESUMO}

Estudo descritivo transversal que teve como objetivo conhecer o comportamento de pessoas com diabetes mellitus em relação à prática de utilização das lancetas e/ou agulhas na automonitorização da glicemia capilar no domicílio. O estudo foi realizado em uma Unidade Básica de Saúde no município de Ribeirão Preto-SP, de agosto de 2008 até julho de 2009. Os dados foram obtidos através de entrevista dirigida, com 57 sujeitos. Os resultados mostraram que $41(71,9 \%)$ pessoas reutilizavam as lancetas e/ou agulhas, na frequência de 1 a 5 vezes $(52,6 \%)$. Todos os sujeitos referiram que não compartilham a mesma lanceta e/ou agulha com outras pessoas. Torna-se necessário incrementar estudos futuros para investigar os riscos e benefícios dessa prática, como também cursos de capacitação em educação em diabetes para os profissionais de saúde, visando atender à complexidade do cuidado dos usuários. Descritores: Diabetes Mellitus; Automonitorização da Glicemia; Equipamentos Descartáveis; Agulhas.

\begin{abstract}
Sectional descriptive study that aimed to understand the behavior of people with diabetes mellitus in relation to the practice of use of lancets and / or needles in self-monitoring of blood glucose at home The study was conducted at the Centro de Saúde Escola Joel Domingos Machado, da Faculdade de Medicina de Ribeirão Preto-SP, from August 2008 to July 2009. Data were collected through direct interviews, involving 57 subjects. The results showed that 41 (71.9\%) people reuse lancets and / or needles, in a frequency of 1-5 times $(52.6 \%)$. All subjects reported they did not share the same lancet and / or needles with others. It is necessary to enhance future studies to investigate the risks and benefits of this practice, as well as training courses on diabetes education for healthcare professionals, aiming to meet the complexity of care for users.
\end{abstract}

Key words: Diabetes Mellitus; Blood Glucose Self-Monitoring; Disposable Equipment; Needles.

\section{RESUMEN}

Estudio descriptivo transversal. Dirigido a entender el comportamiento de las personas con diabetes mellitus en relación con la práctica de uso de lancetas y / o agujas en la automonitorización de la glucosa en la sangre en el país El estudio se realizó en la Centro de Saúde Escola Joel Domingos Machado, da Faculdade de Medicina de Ribeirão Preto en agosto de 2008 a julio 2009. Los datos fueron recolectados a través de entrevistas directas. 57 sujetos participaron. Los resultados mostraron que $41(71,9 \%)$ personas lancetas reutilización y / o agujas, la frecuencia de 5.1 veces (52,6\%). Todos los sujetos informaron que no compartían la misma lanceta y / o agujas con otros. Es necesario aumentar los estudios futuros para investigar los riesgos y beneficios de esta práctica, así como cursos de capacitación sobre educación en diabetes para los profesionales de la salud, con el objetivo de atender a la complejidad de la atención para los usuarios.

Palabras clave: Diabetes Mellitus; Automonitorización de la Glucosa Sanguínea; Equipos Desechables; Agujas. 


\section{INTRODUÇÃO}

O diabetes mellitus (DM) é uma condição crônica que requer gerenciamento contínuo, sendo caracterizado por hiperglicemia e ocasionado por uma deficiência absoluta ou relativa de insulina, influenciando o metabolismo dos glicídios, proteínas, lipídios, água, vitaminas e, durante a sua evolução, na dependência do controle metabólico, podem advir complicações agudas e crônicas ${ }^{(1)}$.

Para atender ao tratamento proposto, temos a prática de insulinoterapia e monitoração da glicemia realizada no domicilio pelas pessoas com DM. No entanto, a prática da reutilização de materiais descartáveis no domicílio pelos usuários com diabetes mellitus é polêmica e controversa no Brasil e no mundo. Dessa forma, o presente estudo tem como objetivo conhecer o padrão de utilização de lancetas e/ou agulhas na automonitorização da glicemia capilar por pacientes da rede pública que são beneficiados pelo programa governamental. A análise dos dados poderá trazer subsídios para melhorar a orientação de cuidados de enfermagem e possivelmente otimizar o uso de recursos públicos na saúde.

\section{REFERENCIAL TEÓRICO}

A Associação Americana de Diabetes (ADA) recomenda que a automonitorização da glicemia capilar no domicílio, assim como outros fatores, façam parte do programa de educação a pessoa com DM. Reforçando assim, a compreensão para a modificação do estilo de vida e melhora da adesão ao tratamento, com estimulo as praticas de autocuidado ${ }^{(2)}$.

A automonitorização da glicemia capilar realizada em aparelho de glicosimetria de uso domiciliar é um excelente recurso utilizado para retratar as flutuações glicêmicas ao longo do dia. É uma ferramenta muito utilizada no acompanhamento das pessoas com DM em esquema de tratamento intensivo, especialmente sob o uso de múltiplas doses diárias de insulina ${ }^{(3)}$.

Em atendimento à Lei Estadual nº. 10782/01 que garante o fornecimento integral de medicamentos e insumos aos indivíduos com diabetes no Estado de São Paulo ${ }^{(4)}$, o município de Ribeirão Preto-SP representado pela Secretaria Municipal da Saúde em um convênio com a Secretaria de Estado, desde 2005 passou a disponibilizar gratuitamente glicosímetro, lancetador, fitas reagentes e lancetas para os indivíduos com diabetes usuários de insulina ${ }^{(5)}$.

Várias estratégias vêm sendo utilizadas pelas famílias, acerca da reutilização de agulhas e seringas descartáveis para a aplicação de insulina ${ }^{(6-8)}$. No entanto, com o incremento do uso de lancetas para o monitoramento da glicemia torna-se necessário conhecer o comportamento das pessoas com diabetes no que se refere ao uso e/ou reuso das lancetas no domicílio.

\section{METODOLOGIA}

Trata-se de um estudo descritivo transversal. O estudo tipo survey visa obter informações quanto à prevalência, distribuição e inter-relações de variáveis de uma população ${ }^{(9)}$. $\mathrm{O}$ estudo descritivo pretende descrever "com exatidão" os fatos e fenômenos de determinada realidade ${ }^{(9)}$.

O estudo foi desenvolvido no Centro de Saúde Escola - Joel Domingos Machado, da Faculdade de Medicina de Ribeirão Preto da Universidade de São Paulo. Primeiramente foi solicitada uma listagem de usuários do Programa de Saúde do Adulto- Doenças Crônico-Degenerativas para a obtenção do número de pessoas com DM cadastradas. De posse da lista foram identificadas 356 pessoas com DM cadastradas no referido Programa. Cabe destacar que este Programa foi implantado pela Secretaria Municipal de Saúde de Ribeirão Preto no período de novembro de 2005 a novembro de 2007.

A amostra foi determinada de forma aleatória, por conveniência, e foi composta por 57 sujeitos. Para a coleta de dados foi utilizado um instrumento considerando as variáveis do estudo, a experiência pessoal do pesquisador e orientador e revisão de literatura $^{(6-8,10,11)}$. O instrumento foi apreciado por quatro juízes com conhecimento especializado no atendimento em DM. Os dados foram obtidos através da técnica de entrevista dirigida, no qual os sujeitos foram convidados a participar do estudo no momento em que aguardavam consulta médica.

Foi realizada a construção do banco de dados com sua validação e dupla alimentação, no programa Microsoft Excel, versão XP (Microsoft Co, USA). Posteriormente, os dados foram importados para o programa SPSS (Statistical Package for the Social Sciences) for Windows, versão 15.0, e submetidos à análise estatística descritiva. Os resultados serão apresentados por meio de média, moda e desvios padrão (DP) no caso de quantitativos.

O projeto de pesquisa foi aprovado pela Comissão de Ética do Centro de Saúde Escola (CSE)-Joel Domingos Machado da FMRP/USP. Protocolo $\mathrm{n}^{\circ} .278$.

\section{RESULTADOS E DISCUSSÃO}

A Tabela 1 mostra as características sócio-demográficas e clínicas dos 57 (100\%) sujeitos. Observa-se o predomínio de mulheres, média de idade de 61 anos, aposentados, com primário completo. Todos possuíam o diabetes tipo 2, com tempo médio de 15 anos de doença. Esses dados corroboram os estudos na temática de pessoas com diabetes que realizam a aplicação de insulina e o automonitoramento da glicemia.

A Tabela 2 mostra as variáveis relacionadas à utilização de lancetas e/ou agulhas para a automonitorização da glicemia capilar no domicílio. Os sujeitos referiram preferência pelo uso dos lancetadores, principalmente pela diminuição da dor e praticidade.

A Tabela 3 mostra a freqüência das reutilizações de lancetas e/ou agulhas, segundo o número de vezes habitual, máximo, mínimo e ideal considerado pelo entrevistado.

Constatou-se que 41 (71,9\%) dos indivíduos com DM que reutilizam a mesma lanceta e/ou agulha, referiram uma freqüência de 1 a 5 (52,6\%) vezes, sendo a média de utilização da mesma lanceta de 5 vezes.

A média de 3,5 vezes foi referida pelos sujeitos como sendo ideal para reutilização da mesma lanceta e/ou agulha. Cabe destacar que um sujeito referiu ter utilizado a mesma lanceta por 30 vezes e outro por 60 vezes. 
Tabela 1 - Distribuição das características sociodemográficas e clínicas das pessoas com diabetes $(n=57)$. Ribeirão Preto-SP, 2009.

\begin{tabular}{|c|c|c|}
\hline Características sociodemográficas & $(\%)$ & média (dp*) \\
\hline Idade (em anos) & & $61,9 \pm 9,5$ \\
\hline Sexo (feminino / masculino) & $68,4 / 31,6$ & \\
\hline Ocupação (aposentados ) & 43,8 & \\
\hline Grau de Escolaridade (primário completo) & 33,3 & \\
\hline $\mathrm{N}^{\circ}$ de Membros na família (entre 1 e 2 ) & 49,2 & \\
\hline Renda familiar (entre um e dois salários mínimos) & 33,4 & \\
\hline \multicolumn{3}{|l|}{ Características clínicas } \\
\hline Diabetes tipo 2 & 100 & \\
\hline Tempo de Diagnóstico (em anos) & & $15,2 \pm 8,5$ \\
\hline Tempo de Aplicação de Insulina (em anos) & & $7,15 \pm 7,5$ \\
\hline Número de aplicações de insulina (duas) & 64,8 & \\
\hline
\end{tabular}

$* d p=$ desvio padrão

Tabela 2 - Distribuição de variáveis relativas à utilização de lancetas e/ou agulhas para a automonitorização da glicemia capilar, segundo o tipo de instrumental em uso, responsável pela realização do teste, procedimento de utilização da lanceta e/ou agulha após $1^{\circ}$ uso, lavagem das mãos e uso de algodão com álcool. Ribeirão Preto-SP, 2009.

\begin{tabular}{lcc}
\hline Tipo de instrumental em uso & $\mathbf{n}$ & \% \\
\hline Agulha descartável & 3 & 5,3 \\
Lancetas & 6 & 10,5 \\
Lancetadores & 48 & 84,2 \\
\hline
\end{tabular}

Responsável pela realização do teste

\begin{tabular}{lcc}
\hline O próprio sujeito & 46 & 80,5 \\
O esposo/esposa & 3 & 5,3 \\
O profissional de enfermagem & 4 & 7,1 \\
Outros (como filho/filha) & 4 & 7,1 \\
\hline
\end{tabular}

\section{Procedimento de utilização da lanceta após $1^{\circ}$ uso}

\begin{tabular}{lcc}
\hline Recoloca o protetor da lanceta e/ou agulha & 9 & 15,8 \\
Passa algodão com álcool na lanceta e/ou agulha & 5 & 8,8 \\
Descarta a lanceta e/ou agulha após $1^{\circ}$ uso & 16 & 28 \\
Outros & 19 & 33,3 \\
\hline
\end{tabular}

\section{Lavagem das mãos}

\begin{tabular}{lcc}
\hline Sim & 54 & 94,7 \\
Não & 3 & 5,3 \\
\hline
\end{tabular}

Uso de algodão com álcool no local do teste

\begin{tabular}{lll}
\hline Sim & 43 & 75,4 \\
Não & 14 & 24,6 \\
\hline
\end{tabular}

Dos $41(71,9 \%)$ indivíduos com DM que referiram reutilizar a lanceta e/ou agulha, 32 (56,1\%) receberam orientação de profissionais da saúde tais como: enfermagem, farmacêutico e médicos na própria unidade de saúde. Todos os indivíduos com DM referiram que não compartilham a lanceta e/ou agulha com outras pessoas.

Dos sujeitos investigados, apenas $2(3,5 \%)$ referiram um episódio anterior de hiperemia nos locais de realização dos testes de glicemia capilar, não procurando um serviço de saúde. Destes, um sujeito considerou que a hiperemia foi ocasionada devido a múltiplas punções no mesmo dedo e o outro pela profundidade da punção. Em relação à qualidade das lancetas e/ou agulhas durante a realização do teste da glicemia capilar, 8 (14\%) sujeitos referiram que suas lancetas e/ou agulhas já entortaram.

A prática da reutilização de materiais descartáveis no domicílio pelos usuários com DM é polêmica e gera controvérsias no Brasil e no mundo, como demonstram alguns estudos sobre o reuso de seringas e agulhas na aplicação de insuli$n a^{(6-8,10-11)}$. Em relação à reutilização de lancetas encontram-se apenas estudos internacionais sobre as complicações e/ou riscos na reutilização e compartilhamento na monitorização da glicemia capilar ${ }^{(12-15)}$. Na literatura nacional ainda não há estudos a respeito da reutilização de lancetas na automonitorização da glicemia capilar em âmbito domiciliar.

A maioria dos indivíduos do presente estudo, aproximadamente $72 \%$, refere reutilização das lancetas. Esse evento é preocupante pela falta de padronização e aprovação do Ministério da Saúde e pela orientação dos fabricantes afirmando que essa prática pode desencadear alterações nos locais de aplicação e danificar o material. No entanto, pessoas com DM utilizam estratégias variadas, muitas vezes, com critério próprio, motivo que tem levado pesquisadores a investigarem o reuso de materiais descartáveis ${ }^{(6)}$.

Dessa maneira, respostas subjetivas foram fornecidas em relação ao motivo de descarte das lancetas, tais como: medo de adquirir uma contaminação e infecção, ao sentir dor na punção ou quando os sujeitos consideravam que a lanceta "parava" de furar o dedo. Foram identificadas ainda dúvidas quanto à permissão e o número ideal de reutilizações das lancetas. Outros indivíduos negaram problema em relação à reutilização, uma vez que somente eles utilizam as mesmas lancetas.

Foram encontradas ainda práticas variadas de reutilização em que pessoas afirmaram recolocar o protetor da lanceta e/ ou agulha, passar algodão com álcool na lanceta e/ou agulha e outras medidas como deixar a lanceta no próprio lancetador. Foi constatada a inexistência da fervura ou lavagem com água fervida, como foi encontrado em outros dois estudos desenvolvidos na prática de reutilização de agulhas para aplicação de insulina ${ }^{(6,14)}$.

É preocupante o uso do álcool na reutilização das lancetas, uma vez que, para atingir o objetivo de desinfecção ou esterilização, apenas o grupo dos aldeídos é indicado, dependendo do tempo de imersão ${ }^{(16)}$. Na literatura, a recomendação para reutilizar a seringa descartável indica que se deve colocar álcool no protetor da agulha e recolocá-lo, armazenando a seringa após o uso ${ }^{(17)}$. No entanto, este procedimento é 
Tabela 3 - Distribuição das frequências de utilização da mesma lanceta e/ou agulha considerando número real, maior, menor, e ideal de vezes referidas pelas pessoas com diabetes $(n=41)$ entrevistadas. Ribeirão Preto-SP, 2009.

\begin{tabular}{|c|c|c|c|c|c|}
\hline Características sociodemográficas & Mínimo & Máximo & Moda & Média & $\left(\mathrm{dp}^{*}\right)$ \\
\hline Freqüência real de uso da mesma lanceta/agulha & 1 & 16 & 2 & 5,2 & $\pm 4,4$ \\
\hline Maior $n^{\circ}$. de vezes de uso da mesma lanceta/agulha & 1 & 60 & 3 & 6,85 & $\pm 9,6$ \\
\hline Menor $n^{\circ}$. de vezes de uso da mesma lanceta/agulha & 1 & 16 & 2 & 3,4 & $\pm 3,7$ \\
\hline$N^{\circ}$ ideal de vezes de uso da mesma lanceta/agulha & 1 & 15 & 2 & 3,5 & $\pm 3,6$ \\
\hline
\end{tabular}

$* d p=$ desvio padrão

desaconselhável, uma vez que, o álcool degrada o silicone da agulha, o que a tornaria rapidamente rombuda e, consequentemente, as punções mais dolorosas ${ }^{(18)}$.

É importante ponderar que a reutilização de agulhas na aplicação da insulina pela ADA e Sociedade Brasileira de Diabetes (SBD) é recomendada pela falta de riscos evidentes e pela presença de aditivos bacteriostático na insulina como o fenol e metacresol que inibem o crescimento bacteriano. Porém, é necessário que o profissional de saúde realize uma avaliação sistemática dos usuários antes de optarem pela reutilização da agulha na aplicação da insulina de acordo com as indicações (boa higiene corporal, acuidade visual adequada, destreza manual e ausência de tremores) e capacidade de receber orientações específicas sobre os possíveis benefícios e riscos e procedimentos para a reutilização ${ }^{(18)}$.

Há necessidade dos serviços reverem suas práticas, no sentido de capacitarem adequadamente os profissionais de saúde e o enfermeiro em particular a realizar uma avaliação periódica desta atividade. Considera-se ainda a importância da criação de protocolos institucionais que avaliem o contexto de saúde e socioeconômico da clientela a fim de direcionar as orientações para pessoas com DM e familiares ${ }^{(6)}$.

Já por parte das pessoas com diabetes, um estudo descreve que essas não aderiram à orientação de trocar a lanceta em cada uso, sendo a lanceta reutilizada em domicílio por várias semanas $^{(19)}$.

O fator econômico relacionado ao alto custo do tratamento e distribuição de insumos para a automonitorização da glicemia capilar pode estar relacionado à prática da reutilização de lancetas e/ou agulhas. Entretanto, neste estudo quase a totalidade dos sujeitos referiram que os insumos adquiridos são suficientes em relação ao número de lancetas adquiridas na unidade de saúde. Alguns sujeitos relataram que o número de lancetas só é suficiente com a prática da reutilização e não quando utilizadas para uso único. Três sujeitos afirmaram preferência pela agulha para aplicar o teste da glicemia capilar, o que poderia estar contribuindo para um desperdício de lancetas adquiridas nos serviços de saúde.

Quanto à quantidade exata de lancetas que recebem por mês, as respostas indicaram números divergentes entre 50, 30, 25 e 20, além daqueles que não souberam informar. Para apenas dois testes diários, é necessário receber, no mínimo, 60 lancetas por mês. A frequência da monitorização da glicemia capilar proposta pela SBD para uma intensificação terapêutica ideal inclui para o tipo 1 três testes ou mais por dia em diferentes horários e para o tipo 2 em uso de insulina três testes por dia em diferentes horários, dependendo do grau de estabilização glicêmica. No total, isso representa um consumo mensal de 90 fitas reagentes de glicemia capilar e 90 lancetas, para no mínimo três testes diários ${ }^{(1)}$. Portanto, apesar dos sujeitos afirmarem que o número de lancetas fornecidas pelo serviço de saúde é suficiente, as quantidades referidas ainda são insuficientes de acordo com o que é proposto pelo SBD ${ }^{(1)}$.

Em relação à reutilização de lancetas e/ou agulhas na monitorização da glicemia capilar, preocupa-nos o compartilhamento por parte das pessoas e dos profissionais, visto que estudos mostram possíveis riscos de transmissão de hepatite $B$ em que a infecção pode ter ocorrido pelo compartilhamento da lanceta em instituições de saúde, e não em domicílio(9-11). Outros estudos mostraram que lancetas para punção de dedo previamente usadas foram alocadas no mesmo local onde estavam as lancetas não utilizadas. Essa prática poderia contribuir para o reuso e, consequentemente, o compartilhamento nos procedimentos de monitorização da glicemia capilar em instituições de saúde ${ }^{(9-10)}$.

Em contrapartida, a maioria dos sujeitos no presente estudo apresentou noção da importância da prática do uso de técnica asséptica para evitar complicações no local da punção, realizando a lavagem das mãos e uso de algodão com álcool. Estes dados pressupõem a eficácia do trabalho educativo do enfermeiro quanto às orientações contínuas sobre a importância das lavagens das mãos ${ }^{(14)}$. Da mesma maneira, todos os entrevistados estavam orientados quanto à importância do não compartilhamento das lancetas, evitando assim a contaminação de terceiros.

Quanto às complicações e/ou riscos na reutilização de lancetas e/ou agulhas na monitorização da glicemia, dois sujeitos referiram ter sofrido alterações locais de realização dos testes de glicemia capilar, tal como hiperemia.

Um estudo refere infecções locais nos dedos de duas pessoas devido à reutilização de agulhas e/ou lancetas por várias semanas, mesmo com orientação para descartá-las após o uso ${ }^{(19)}$. Essas lesões foram submetidas a um tratamento local e sistêmico, não havendo melhora e necessitando da amputação distal dos dedos acometidos. Múltiplas punções no mesmo local e com a mesma lanceta pode ter contribuído 
para a infecção local e um controle metabólico ineficaz pode ter impedido a cura, resultando nas amputações das falanges distais. Estes dois casos sugerem que as pessoas com DM, em particular aqueles com mau controle metabólico, devem receber reforço na orientação para a troca de agulhas descartáveis e lancetas para automonitorização da glicemia capilar.

Indivíduos com complicações do DM, que apresentam comprometimento visual, aumentam sua exposição às punções de dedo, devido à necessidade de realizar múltiplas punções para adquirir uma única amostra de sangue para o teste glicêmico. A falange distal é uma das maiores superfícies contaminadas, além de ser mais sensível, podendo colaborar para o desenvolvimento de uma lesão. Assim outros locais tais como lóbulo da orelha, antebraço, podem e devem ser utilizados durante a punção para o teste de glicemia ${ }^{(20)}$.

\section{CONCLUSÃO}

Deve-se considerar que, se por um lado à distribuição de insumos é suficiente e a prática da reutilização de lancetas e/ou agulhas ocorre como o resultado do presente estudo mostrou, desperdícios podem acontecer. Por outro lado, se a distribuição de insumos é insuficiente, a reutilização acaba ocorrendo para viabilizar o monitoramento da glicemia capilar no domicílio.

A educação em saúde deve buscar desenvolver habilidades para solucionar problemas e promover a integralidade da atenção à saúde ao usuário com DM, visto que a questão da prática da reutilização de lancetas na automonitorização da glicemia capilar é decorrente da necessidade do manejo do DM no cotidiano dos usuários.

Destaca-se a importância dos profissionais orientarem o não compartilhamento das lancetas e/ou agulhas para evitar a transmissão do vírus de hepatites, a necessidade da lavagem das mãos, e o uso do algodão com álcool nos dedos a fim de evitar a infecção local.

Se há realmente segurança em reutilizar as lancetas, esta recomendação deveria ser normatizada pelo Ministério da Saúde, uma vez que este se responsabiliza pela distribuição dos insumos no tratamento e controle do diabetes. Por outro lado, temos que o Ministério da Saúde ainda não protocolou orientações frente ao uso de lancetas na automonitorização da glicemia capilar e há necessidade de maiores evidências na temática.

Nesta direção, a normatização pelo Ministério da Saúde por meio da implementação de protocolo contendo as orientações frente ao uso de lancetas na automonitorização da glicemia capilar, permitiria que os profissionais orientassem as pessoas com DM quanto aos riscos e benefícios desta prática, atendendo as necessidades reais das mesmas. Evitaria também conflitos éticos por parte dos profissionais que por compreenderem a necessidade dos usuários direcionam recomendações para a reutilização de lancetas sem padronização, sem embasamento científico e sem respaldo dos órgãos competentes.

Frente aos resultados obtidos neste estudo, conclui-se ser necessário incrementar estudos futuros observando os riscos e benefícios dessa prática.

\section{REFERÊENIAS}

1. Sociedade Brasileira de Diabetes. Diretrizes da sociedade brasileira de diabetes. São Paulo: SBD; 2011.

2. American Diabetes Association. Tests of glycemia in diabetes. Diab Care 2004;27(Suppl 1):91-3.

3. Oliveira $\mathrm{CH}$, Berger K, Souza SC, Marui S. Monitorização continua de glicose: analise critica baseada em experiência ao longo de um ano. Arq Bras Endocrinol Metabol 2005;49(6):983-90.

4. São Paulo. Lei n 10.299, de 22 de dezembro de 2004. Dispõe sobre as normas de proteção à pessoa diabética incluindo o fornecimento de medicamento e a monitorização da glicemia capilar aos usuários diabéticos cadastrados em programas de educação em diabetes. Diário Oficial do Estado de São Paulo, 22 dez 2004.

5. Secretaria Municipal da Saúde de Ribeirão Preto. Protocolo de atendimento em hipertensão e diabetes. SMSRP: Ribeirão Preto; 2006. [acesso em 25 fev 2008]. Disponível em: <http://www.ribeiraopreto.sp.gov.br/ssaude/ programas/cronico/prot-hipertensao.pdf $>$

6. Amparito RVC, Grossi SAA. Reutilização de seringas descartáveis no domicílio de crianças e adolescentes com diabetes mellitus. Rev Esc Enferm USP 2005;41(2):187-95.

7. Souza CR, Zanetti ML. Reutilização de seringas descartáveis: frequência e custos para a administração de insulina no domicílio. Rev Latino-Am Enferm 2001;(9):47-54.

8. Stacciarini TSG. Processo de administração da insulina no domicílio dos usuários com Diabetes Mellitus acompanhados pela Estratégia Saúde da Família. Ribeirão Preto. Dissertação [Mestrado em Enfermagem]- Escola de Enfermagem de Ribeirão Preto da Universidade de São Paulo; 2007.

9. Polit DF, Hungler BP. Fundamentos de pesquisa em Enfermagem. 3. ed. Porto Alegre: Artes Médicas; 1995.

10. Teixeira CRS, Zanetti ML, Ribeiro KP. Reutilização de seringas descartáveis: frequência e custo para administração de insulina no domicilio. Rev Latino-Am Enferm 2001;9(5):47-54.

11. Castro ARV, Graziano KU, Grossi SA. Alterações nos locais de aplicação de insulina e nas seringas reutilizadas pelos pacientes diabéticos. Rev Gaúch Enferm 2006;27(1):27-34.

12. Centers for Disease Control and Prevention. Transmission of hepatitis B virus among persons undergoing blood glucose monitoring in long-term-care facilities - Mississippi, North Carolina, and Los Angeles County, California, 2003-2004. Morb Mortal Wkly Rep 2005;54(9):220-3. 
13. Quale JM, Landman D, Wallace B, Atwood E, Ditore V, Fruchter G. Déjà vu: nosocomial hepatitis $B$ virus transmission and fingerstick monitoring. Am J Med 1998;105(4):296-301.

14. Khan AJ, Cotter SM, Schulz B, Hu X, Rosenberg J, Robertson $\mathrm{BH}$, et al. Nosocomial transmission of hepatitis $B$ virus infection among residents with diabetes in a skilled nursing facility. Infect Control Hosp Epidemiol 2002;23(6):313-18.

15. Centers for Disease Control and Prevention. Nosocomial transmission of hepatitis B virus associated with a springloaded finger stick device - California. Morb Mortal Wkly Rep 1990;39(35):610-13.

16. Secretaria da Saúde de São Paulo. Centro de Apoio ao Desenvolvimento das Ações Integradas de Saúde. Organização do Centro de Material e noções de esterilização. Secretaria da Saúde de São Paulo; 1993.

17. Hissa MN, Montenegro RM, Colares FAN. Reutilização de seringas descartáveis de insulina: diminuição de custos no tratamento do diabetes insulino-dependente. Arq Bras Endocrinol Metab 1987;31(4):78-80.

18. American Diabetes Association. Insulin administration (position statement). Diab Care 1999;22(Supl 1): S121-4.

19. Monami M, Mannucci E, Masotti G. Finger sepsis in two poorly controlled diabetic patients with reuse of lancets, Diab Care 2002;25(6):1103

20. Suzuki Y, Atsumi Y, Matsuoka K. Finger infection resulting from self-monitoring of blood glucose and a new aid for reducing risk, Diab Care 1998;21(8):1373-4. 